\title{
Assessment Methods, Problems and Training Needs of Public High School Teachers in English
}

\author{
Ronald Candy S. Lasaten
}

\begin{abstract}
Using the descriptive research design, this study aimed to determine and analyze the assessment methods, problems and training needs of public high school teachers in English. The study involved 93 Grade 9 public high school teachers in English. A survey-questionnaire was used to gather the needed data. The data were statistically treated using frequency, rank and mean. Findings reveal that multiple choice ranks first among the assessment methods used by the teachers. In terms of assessment problems along testing- and test item-related problems, the teachers indicate that time for checking is their greatest concern. Meanwhile, it is found out that attitude and behavior of students are the greatest problems of the teachers along student-related problems. As regards problems on tests in general, quality of tests, particularly on the authenticity, reliability and validity of tests, emerge to be their greatest concern. As regards the teachers' training needs, assessment in general, encompassing assessment, measurement, testing and evaluation, emerge as their priority.
\end{abstract}

Index Terms-Assessment methods, assessment problems, assessment training needs, public high school teachers in English.

\section{INTRODUCTION}

Classroom assessment has continuously become one of the concerns in educational institutions. As time passes by, new assessment practices in schools have been adapted to suit the need of the ever-changing curriculum.

Primarily, teachers are the ones greatly affected when innovations in the curriculum are implemented. They make changes in their classroom practices to suit them to the new curriculum. Indeed, teachers have great concern on the quality of classroom assessment they perform. Several literatures on classroom assessment delineates that teachers have to develop their assessment skills [1]-[6]. In recent studies, it was found out that teachers use varied assessment techniques and tools, even if they are not adequately equipped with skills in classroom assessment [7]-[10]. Less attention is given, however, on how teachers use their assessment practices to improve classroom instruction and student learning.

According to [11], assessment is a systematic and logical means of gathering information about what students know and can do. Such information may be sourced through observation of students during their learning activities, examining the results of their learning activities or testing their knowledge and skills. Traditionally, teachers use assessment results as bases in giving grades to their students. However, these days,

Manuscript received February 20, 2016; revised June 15, 2016.

R. C. S. Lasaten is with the Mariano Marcos State University College of Teacher Education (MMSU-CTE), Laoag City, 2900, Philippines (e-mail: ronaldcandylasaten@yahoo.com.ph). teachers use assessment not only as basis for grades but also for improving classroom instruction and student learning.

Indeed, classroom assessment includes a wide array of tasks from constructing tests and performance measures, to grading, interpreting test scores, communicating test results, and using assessment results in making decisions. It is then imperative for teachers to know the strengths and weaknesses of each of the assessment methods used. They should choose right formats to assess student achievements [5]. Tests items should manifest content validity [1]. They should also be geared towards developing higher-order thinking skills among students. In performance assessment, reliability and validity can be improved through the use of measurable, observable and clearly defined performance standards [1]; [12], [13], descriptive scoring rubrics, varied samples of behaviors evaluated by several judges [10], and recording results during assessment [14]. Improving and revising teacher-made tests based on item analysis is also necessary [2]; [15]. Assessment, therefore, involves review of evidence of learning such as journal entries, written work, portfolios, skill demonstrations, and performance in learning activities, test results and rubrics ratings which cover a period of time and should reveal the progress of students in competencies.

The use of assessment is indeed critical in informing and guiding instruction. The use of various assessment tools would help teachers identify which instructional strategies are efficient and appropriate for their learners. Through assessment, the teachers are given feedback to improve their instruction. Therefore, assessment can be used to enhance classroom practices and plans. Undeniably, assessment will always be used as information for students, parents, and administrators. Traditionally, this information was articulated quantitatively by grades. Now, this information is used to allow students to reflect, track and monitor their own learning as they become self-motivated and self-directed learners. Moreover, data on assessment may serve as basis for improving curriculum and program offerings [16].

Teachers have the control to assessments for they are familiar with their students, curriculum, content, and current practices. Further, teachers exactly know the aims and goals of the curriculum that guide them in determining aspects that are to be assessed. And since they have in control of the assessment process, their assessment methods, problems and trainings needs have to be determined so as to improve their assessment practices, eventually leading to improved instruction and learning.

In this context, the Grade 9 teachers in English of the public secondary schools of Ilocos Norte are taken as subjects in the study. These teachers are believed to have concerns about classroom assessment as they articulated it during the 
Regional Mass Training for Grade 9 Teachers in English. Interestingly, tracking the teachers' assessment methods, problems and training needs is one of the best ways for them to be informed and guided in their instruction.

\section{OBJECTIVES OF THE STUDY}

The attitude and perception of teachers towards classroom assessment may influence the way they conduct their classroom instruction. This study was designed to determine and analyze the assessment methods, problems, and training needs of Grade 9 public high school teachers in English of the three school divisions of the province of Ilocos Norte-the Division of Ilocos Norte, Laoag City and Batac City. It is hoped that through this study, the teachers would be informed of their strengths and weaknesses along the area so they would recognize what are supposed to be improved and strengthened in them.

\section{SIGNIFICANCE OF THE STUDY}

Assessment of learning is a vital component of the teaching and learning process. In fact, it is one of the powerful educational tools for promoting learning [17]. Its impact and effect on the teaching and learning process make it a critical factor for school improvement [18]. Assessment, in general, is an important task of every teacher and school, especially that it can be used to promote teaching and learning. Thus, this study is primarily significant to teachers, students and school administrators.

The teachers of English, in particular, will greatly benefit from the result since the concern of the study is directly drawn from them. Being familiar with the rationale behind classroom assessment gives the teachers a wider perspective and understanding of their classroom practices. Through this study, they would be given a true picture of what they are doing inside their classrooms, particularly their instruction. They would be informed of their strengths and weaknesses and of their needs as evaluators of learning. Hence, the result could serve as basis in the improvement of their classroom assessment practices.

The result of the study could also benefit the students since they are the once subjected to assessment given by their teachers. Through this study, the students' learning could be properly evaluated using appropriate assessment tools. Thus, the students would be exposed to varied types of assessment that could help develop their full potentials as individuals.

Administrators could also use the result of the study as basis in developing trainings, seminars and programs which could help address their teachers' needs of assessment. Most importantly, it serves as basis for the evaluation of the English program being offered in schools.

\section{THEORETICAL AND CONCEPTUAL FRAMEWORK}

Significantly, this study is anchored to Continual Improvement Theory. The theory states that teachers are determined and motivated to implement changes. Obviously, they are curious innovators, willing to try out new things.
However, teachers work in isolation most of the time. They discover what works and does not work in their classroom and eventually implement changes to improve their practice. Education is so important in the changing world, though, teachers have to take these kinds of individual practices and formalize them. In this way, assessments could inform them to formally discover the results of innovations, discern on other effective educational practices and share these to contribute in the body of knowledge.

Based on the theory, the study has come up with its conceptual framework as illustrated in Fig. 1. The figure shows that the results of identifying and analyzing the assessment methods, problems and training needs of the Grade 9 teachers in English may be served as feedback for improved learning and instruction.

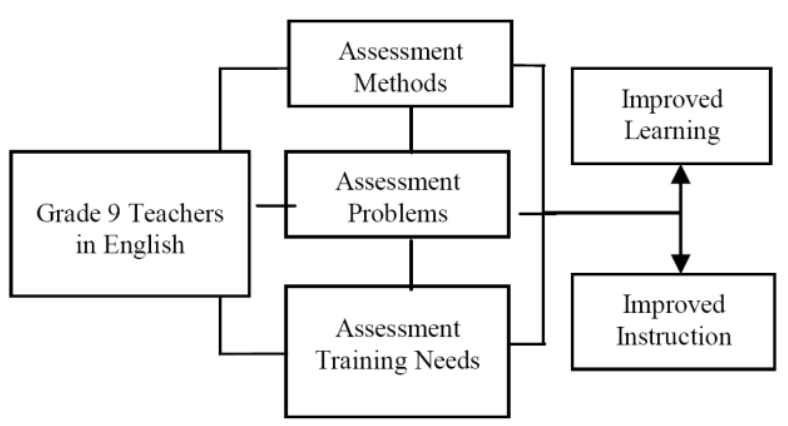

Fig. 1. The Research paradigm.

\section{Methodology}

This study used the descriptive research design. Descriptive research is used to gather data concerning the current status of a subject or phenomenon being studied. Such research design was appropriate for the present study since the study aimed to collect data pertinent to assessment methods, problems and trainings needs of teachers in English and describe the way things are with respect to conditions in a situation.

The respondents involved in the study were the 93 Grade 9 teachers in English from the three school divisions, namely: a) Division of Ilocos Norte; b) Division of Laoag City; and c) Division of Batac City. These teachers, who came from secondary public schools, were the ones who participated in the Regional Mass Training for Grade 9 Teachers in English.

To gather the needed data for the study, a survey instrument based on Assessment Practices Inventory (API) by [19] was used. The instrument was developed based on the literatures on classroom assessment [2]. A table of specifications was used to generate the items. Afterwards, its content validity was tested. The instrument consisted of three parts which gather information on assessment methods, problems and training needs of teachers in English. The instrument was tried out twice with the teachers. Later, it was improved and modified based on the result of the item analysis and feedback of the teachers.

To validate the results of the study, a one-on-one interview was conducted to selected teachers whose responses are in congruence to the findings. Significantly, this was done to further justify and intensify their responses in the survey conducted. According to [20], interviewing is best used when 
conducting intensive case studies of a few selected individuals.

The data gathered from the survey were tabulated, interpreted and analyzed using statistical tools such as frequency, rank and mean.

\section{RESULTS AND DisCUSSIONS}

This section presents the results and findings of the study. It presents tables showing the assessment methods, problems and training needs of the Grade 9 teachers in English. Also, it relates descriptions and analyses of the results and their implications to teaching and learning process.

\section{A. Assessment Methods Used by Teachers in English}

The methods commonly used by teachers in assessing student learning include the paper and pencil tests, performance or authentic assessment, portfolio assessment, and product-based assessment. Interestingly, one of the concerns of the study is to determine the assessment methods used by the teachers in English. Along this area of concern, Table I shows the result.

TABLE I: AsSESSMENT METHODS USED BY THE TEACHERS

\begin{tabular}{ccc}
\hline \hline Assessment Methods & $f$ & $r$ \\
\hline Paper and Pencil & & 1 \\
Multiple choice & 93 & 5 \\
Essay test & 83 & 2 \\
Matching type & 89 & 4 \\
Cloze test & 86 & 3 \\
True or false & 81 & 6 \\
Short answer & & \\
Others (identification, & 9 & 10 \\
enumeration, & & 8 \\
problem-solving tasks, & & 9 \\
concept mapping) & 75 & 7 \\
Performance Assessment & 67 & \\
Portfolio Assessment & 78 & \\
Product-based Assessment & & \\
\hline \hline &
\end{tabular}

Among the assessment methods used by the teachers in English, the most commonly used methods are objective tests such as multiple choice (93), matching type (89), true or false (86) and cloze test (85). Traditional tests such as essay (83) and short-answer items (81) are also utilized. On the other hand, non-traditional methods such as product-based assessment (78), performance assessment (75) and portfolio assessment (67) are likewise implemented. Other assessment methods used by the teachers were identification, enumeration, problem-solving tasks and concept mapping.

Such result can be supported by the findings in the study of [21] that most teachers use the paper and pencil tests (objective and traditional assessment) due to the fact that this can be easily facilitated, checked and scored. Moreover, results of these forms of assessment can be easily interpreted and translated into grades since these types of test require objective answers.

Also, the result can be supported by the result of the study of [22] which concentrated on the assessment and grading practices of 19 high school Mathematics teachers. Their study revealed that tests and quizzes, which are forms of paper and pencil tests, were the most frequently used assessment tools by the teachers.

Written projects or interviews with students were used by the teachers as other forms of assessment.

On the other hand, [23] affirms that teachers seldom use portfolio assessment for it requires long preparation and procedure. In addition, it is difficult to assess since rubrics and scoring guides have to be used in the assessment process. Moreover, this method of assessment has not yet gained familiarity to the teachers, thus, it is not often used by them.

Indeed, the result only shows that the teachers widely use paper and pencil tests, particularly multiple choice type of test. This implies that the teachers are still confined to conventional practices of assessment, since paper and pencil tests are considered traditional cognitive form of assessment [11]. The teachers lack skills to formulate meaningful ways to measure their students' learning. Meanwhile, the least used assessment method is portfolio assessment, which is a form of alternative assessment. This implies that the teachers are not yet familiar with this form of assessment; thus, they are not using this frequently.

Such implications from the result of the study are related to the result of the study of [24] revealing that the teachers involved in the study had inadequate ways of assessing their students. They are confined to the assessment methods they are familiar with. Unfortunately, these teachers primarily used tests just to assess their students.

In an interview conducted, most of the teachers find alternative or authentic assessment difficult to facilitate. They find alternative or authentic assessment laborious and time-consuming as compared to that of paper-and-pencil test. However, they understand the importance of using such form of assessment. Thus, they conveyed their need of trainings and seminars on alternative or authentic assessment to deepen their understanding of this form of assessment. To be familiar with the use of alternative or authentic type of assessment requires constant practice. Thus, the teachers should be encouraged to use these forms of assessment to assess their students' learning. Having knowledge of these forms of assessment is different from being actually using them in real classroom setting.

In relation to the result, [24], through his study, found out that teachers understand that paper-and-pencil tests help teachers to check what students have achieved. However, they also believe that other methods and tools must be used in order to understand the quality of teaching and learning. Indeed, [25] reports teachers having positive attitudes toward classroom assessment but having limited knowledge of it.

\section{B. Assessment Problems of Teachers in English}

Identifying the teachers' problems on assessment is also one of the concerns of the study. The result in this area of concern could serve as basis in appropriately addressing the assessment problems that confront the teachers in English. Table II presents the assessment problems of the teachers.

Along testing- and test item-related problems, time for checking (83) is considered by the teachers as their greatest problem, making it at the top rank, followed by reproduction of test papers (65), test preparation (65) and types of questions/test (62). Such result is indicated due to the fact that teaching profession requires so much time, thus, teachers 
have no enough time to check the test papers of their students; they are busy with other instructional activities of which they are also obliged to attend to.

In relation to the attained result, [26] contends that if assessment is not embedded within the teaching process, teachers will see it as a separate activity that demands extra time. In the interview conducted, the teachers complained that they have no enough time to check papers especially that most of the classes they are handling consist of more than 50 students. Worst, most of the teachers are given at least a six-hour class instruction every day leading them no more time to plan and prepare appropriate assessment tools.

TABLE II: ASSESSMENT PROBLEMS OF THE TEACHERS

\begin{tabular}{|c|c|c|}
\hline Assessment Problems & $f$ & $r$ \\
\hline \multicolumn{3}{|c|}{ Testing- and Test Item-related Problems } \\
\hline Time for checking & 83 & 1 \\
\hline Reproduction of test papers & 65 & 2.5 \\
\hline Writing directions & 24 & 8 \\
\hline Test preparation & 65 & 2.5 \\
\hline Coverage of the test & 35 & 6 \\
\hline Types of question or test & 62 & 4 \\
\hline Scheduling of test & 30 & 7 \\
\hline Errors in test & 40 & 5 \\
\hline \multicolumn{3}{|c|}{ Student-related Problems } \\
\hline Low/poor performance & 74 & 2.5 \\
\hline Attitude and behavior & 77 & 1 \\
\hline Guessing on the test & 74 & 2.5 \\
\hline Poor preparation for the test & 56 & 5 \\
\hline Cheating & 66 & 4 \\
\hline \multicolumn{3}{|l|}{ Testing in General } \\
\hline \multicolumn{3}{|l|}{ Quality of tests: reliability } \\
\hline \multicolumn{3}{|l|}{ Appropriateness of items } \\
\hline to learners & 45 & 4 \\
\hline Lack resources & 47 & 2 \\
\hline Interpreting test results & 46 & 3 \\
\hline
\end{tabular}

Meanwhile, the teachers indicated writing directions (24), schedule of test (30), coverage of test (35), and errors in test (40) as their least concern in assessment.

In terms of student-related problems, the teachers indicated students' behavior and attitude (77) as their greatest problem while their least problem is their students' poor preparation for the test (55). These results show that the students have unfavorable attitude towards assessment.

According to the teachers interviewed, their students either complain or negotiate to postpone whenever they are asked to undergo assessment. Some others show tantrums or manifest fear on their faces, indicating unpreparedness and restlessness to undergo the assessment process. Many of them find assessment a fault-finding activity, making them uninterested to participate. The students even testify that after taking a test, they forget virtually all the information they learned for the test. However, most of the teachers believe that their students prepare themselves for assessment. Thus, students' preparation for assessment is not a big problem to the teachers.

As regards testing in general, the teachers' greatest problem is on the quality of tests (51). This only means that the teachers have no idea or knowledge as to how to determine the validity and reliability of the tests they give to their students. This implies that they are not so sure whether they giving quality exams or not to their students. Most of the teachers agreed that whenever they are not ready to give exams, they have the tendency to use exams they used in the past. Some modify the items, some do not. With this practice of the teachers, it can be implied that assessment is taken for granted by the teachers and that its value is meaningless and insignificant to teaching and learning. More so, the teachers may not find assessment as an engaging endeavor in their profession. They find it laborious and complicated. Thus, they simply ignore its importance.

On the other hand, appropriateness of items to learners (45) is not so much a problem to the teachers. This only means that the teachers are aware that they are giving appropriate test items to their students during exams.

\section{Assessment Training Needs of Teachers in English}

Interestingly, the teachers involved were also asked to indicate their assessment training needs. It is believed that knowing the training needs of the teachers in assessment is significant such that it could serve as bases in improving the teachers' assessment practices. The following table shows that assessment training needs of the teachers in English.

Based on the Table III, it is evident that the teachers indicated assessment in general (68) as their top rank training need, followed by trends in assessment and testing (65) and others (62), which include teaching methods, use of computer applications, all trainings related to testing, etc. The results only mean that the teachers still have a lot of concerns about assessment in general.

TABLE III: ASSESSMENT TRAINING NEEDS OF THE TEACHERS

\begin{tabular}{ccc}
\hline \hline Assessment Training Needs & $f$ & $r$ \\
\hline $\begin{array}{c}\text { General: Assessment, measurement, } \\
\text { testing, evaluation }\end{array}$ & 68 & 1 \\
Test construction and item writing & 54 & 7 \\
Trends in assessment and testing & 65 & 2 \\
Alternative Assessment: Portfolio & & \\
$\quad \begin{array}{l}\text { and performance assessment } \\
\text { Test item review and item analysis } \\
\text { Test interpretation and feedback } \\
\begin{array}{c}\text { Others: Testing methods, use of } \\
\text { computer applications, all }\end{array}\end{array}$ & 57 & 4 \\
trainings related to testing, etc. & 56 & 6 \\
\hline \hline$n=93 \quad 62$ & 3 \\
\hline
\end{tabular}

The result can be supported by the result of the study of [3] showing that teachers are not adequately equipped with skills in classroom assessment due to lack of training. Thus, the teachers have to attend more training on assessment so that their knowledge will be improved and that this will lead change into their assessment practices. Likewise, the teachers need to consider classroom assessment an essential component of the teaching-learning process.

The result of the study conforms to the belief of [27] that assessment is an essential aspect of the teaching-learning process for it provides teachers feedback as to how their students construct and acquire their own learning. Furthermore, classroom assessment helps teachers gauge where the students are and what more the students need to learn. [28] contend that a teachers need to know the entry 
skills and knowledge of their students, so they can make effective and appropriate plans for instruction. Thus, assessment, in general, is a great need. As what most of the teachers mentioned in the interview, they conveyed that they still have a lot of concerns about assessment, especially that there is already a shift of paradigm in classroom teaching. The innovations (e.g. $\mathrm{K}$ to 12 Curriculum) introduced in educational system are making significant changes in the teachers' view of assessment and their assessment practices.

The implication drawn from the result is also supported by the claim of [29] that teachers have to attend trainings on assessment so that they will be informed of the new trends and issues in assessment and be eventually equipped with new skills that lead to better assessment practices. Through trainings, the teachers become more proficient in the assessment process leading to modified behavior that contributes to the attainment of education's goals and objectives.

Meanwhile, test construction and item writing (54), test interpretation and feedback (55), test item review and item analysis (56), and alternative assessment (57) are observed to be the topics which the teachers need less training.

Relative to the attained result, the teachers expressed during the interview that these topics are not so much of their need either because they have been doing these (e.g. test construction and item writing, test interpretation and feedback). Some are hesitant to venture on these endeavors, especially that some of these topics (e.g. item analysis and alternative assessments) require in-depth understanding before one can finally carry them out. These assessment procedures are not necessarily required for the teachers to undertake.

It can also be implied from the result that some of the teachers have no plan to carry out such practices due to their limited time. According to some of the teachers, they are willing to venture into such processes only if they have ample time to do them. Some of them mentioned that they have other concerns in school and that they have only limited time to reflect on their assessment practices.

Ref. [15] emphasized that teachers should continuously improve and modify their tests based on the results of their item analysis so that sensible judgment on students will be made and that school improvement will be attained [30].

\section{CONCLUSIONS}

In the light of the findings, this study concludes that the public high school teachers in English from the three schools division of Ilocos Norte commonly use multiple choice type of test. The said teachers are still confined to the paper and pencil test. They have not yet fully embraced the forms of alternative and authentic assessments such as portfolio, performance and product-based assessments in their classroom instruction

Further, the study concludes that time for checking, attitude and behavior of students and quality of tests are their common assessment problems. The teachers have no ample time to check papers due to many activities and programs conducted in school. Moreover, the conduct of tests has negative impact to the students causing them to show unfavorable attitude and behavior towards testing and assessment. Moreover, the teachers have dilemma on the reliability and validity of the tests they give to their students. Thus, they are not certain whether or not they are giving their students appropriate tests.

Lastly, this study concludes that the teachers have assessment training needs, particularly on assessment, measurement, testing and evaluation, in general.

\section{RECOMMENDATIONS}

From the conclusions drawn, it is recommended that the public high school teachers in English from the three schools division of Ilocos Norte have to attend more seminars and trainings on assessment so they can widen their knowledge of the different methods and approaches of assessment and be given strategies or mechanisms on how to handle assessment problems being encountered. Likewise, it is recommended that a training addressing the teachers' assessment needs has to be proposed and conducted. Moreover, a similar study has to be conducted to further validate the result of the present study.

Indeed, classroom assessment is an essential component of the teaching-learning process. Thus, improving the assessment skills of the teachers in English should be prioritized. School administrators and officials should realize that improving educational standards is not only about effective management, construction of school buildings, and availability of teachers and books. This also includes quality classroom practices of which classroom assessment is of crucial aspect.

\section{REFERENCES}

[1] P. W. Airasian, Classroom Assessment, New York: McGraw-Hill, 1994, pp. 162-178.

[2] L. M. Carey, Measuring and Evaluating School Learning, Boston: Allyn and Bacon, 1994, pp. 256-264.

[3] R. G. O'Sullivan, and M. K. Chalnick, "Measurement-related course work requirements for teacher certification and recertification," Educational Measurement: Issues and Practices, vol. 10, pp. 17-19, March 1991.

[4] W. D. Schafer, "Essential assessment skills in professional education of teachers," Educational Measurement: Issues and Practice, vol. 10, pp. 3-6, March 1991.

[5] R. J. Stiggins, "High quality classroom assessment: What does it really mean?" Educational Measurement: Issues and Practice, vol. 11, pp 35-39, April 2012

[6] R. J. Stiggins, Student-Centered Classroom Assessment, 2nd ed. Upper Saddle River, NJ: Prentice-Hall, 1997, pp. 212-219.

[7] J. R. Hills, “Apathy concerning grading and testing," Phi Delta Kappa, vol. 72, pp. 540-545, August 1991

[8] S. B. Nolen, T. M. Haladyna, and N. S. Haas, "Uses and abuses of achievement test scores," Educational Measurement: Issues and Practice, vol. 11, pp. 9-15, January 1992.

[9] B. S. Plake, "Teacher assessment literacy: Teachers' competencies in the educational assessment of students," Mid-Western Educational Researcher, vol. 6, pp. 21-27, January 1993.

[10] S. B. Dunbar, D. M. Koretz, and H. D. Hoover, "Quality control in the development and use of performance assessments," Applied Measurement in Education, vol. 4, pp. 289-303, April 1991.

[11] N. L. Navarro and R. de Guzman-Santos, Authentic Assessment of Student Learning Outcomes: Assessment of Learning 2, 2nd ed. Quezon City: Lorimar Publishing, Inc., 2013, pp. 48-49.

[12] J. B. Baron, "Strategies for the development of effective performance exercises," Applied Measurement in Education, vol. 4, pp. 305-318, April 1991.

[13] R. J. Shavelson, G. P. Baxter, and J. Pine, "Performance assessment in science," Applied Measurement in Education, vol. 4, pp. 347-362, April 1991. 
[14] R. J. Stiggins and N. J. Bridgeford, "The ecology of classroom assessment," Journal of Educational Measurement, vol. 22, pp. 271-286, December 1985.

[15] R. J. Gregory, Psychological Testing: History, Principles, and Applications, 2nd ed. Boston: Allyn and Bacon, 1996, pp. 145-152.

[16] R. Cartwright et al., Student Learning Outcomes Assessment Handbook, Maryland: Montgomery College, 2009, pp. 16-30.

[17] Assessment Reform Group, Assessment for Learning: Beyond the Black Box, Cambridge: University of Cambridge School of Education, 1999, pp. 473-487.

[18] C. Gipps, Assessment: A Teachers' Guide to the Issues, London: Hodder and Stoughton, 1990, pp. 12-18.

[19] Z. Zhang and J. A. Burry-Stock, Assessment Practices Inventory, Tuscaloosa, AL: The University of Alabama, 1994, pp. 323-342.

[20] S. B. Merriam, Qualitative Research and Case Study Applications in Education, San Francisco, California: Jossey-Bass Publishers, 2001, pp. $178-180$

[21] Z. Zhang, "Investigating teachers' self-perceived assessment practices and assessment competencies on the assessment practices inventory," Ph.D. Dissertation, The University of Alabama, Tuscaloosa, Alabama, 1995.

[22] C. E. Beckmann, S. L. Senk, and D. R. Thompson, "Assessment and grading in high school mathematics classroom," Journal for Research and Mathematics Education, vol. 28, pp. 187-215, December 1997.

[23] C. S. Taylor, "Using portfolios to teach teachers about assessment: How to survive," Educational Assessment, vol. 4, pp. 123-147, July 1997.

[24] W. J. Banda, "Classroom assessment in Malawi: Teachers' perceptions and practices in Mathematics," Ph.D. dissertation, Virginia Polytechnic Institute and State University, Blacksburg, Virginia, 2005.

[25] C. M. Selemani-Mbewe, "Knowledge, attitude and practice of classroom assessment: Implications on the implementation of school-based assessment in Malawi," M.S. thesis, University of Massachusetts, Amherst, 2002.

[26] S. Diene, Toward Understanding Teacher Change, Urbana: Center for the Study of Reading, 1993, pp. 26-38.

[27] D. C. Phillips, Constructivism in Education: Options and Second Options on Controversial Issues, Chicago: The National Society for the Study of Education, 2000, pp. 135-138.
[28] J. G. Ampiah, K. Hart, B. Nkhata, and D. M. C. Nyirenda, "Teachers' guide to numeracy assessment instrument," DfID-funded research project report, Nottingham: University of Nottingham, 2003.

[29] S. L. Wise, L. E. Lukin, and L. L. Roos, "Teacher beliefs about training in testing and measurement," Journal of Teacher Education, vol. 42, pp. 37-42, August 1991.

[30] R. J. Stiggins and N. F. Conklin, In Teachers' Hands: Investigating the Practices of Classroom Assessment, Albany: State University of New York Press, 1992, pp. 123-134

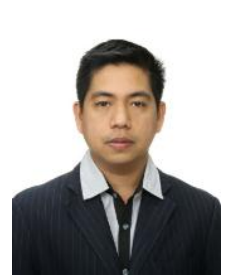

Ronald Candy S. Lasaten is from the City of Batac, Ilocos Norte, Philippines. He was born on January 16 1981. He earned his doctor of philosophy degree in applied linguistics at the Mariano Marcos State University (MMSU) Graduate School, Laoag City, Philippines in 2012

$\mathrm{He}$ is presently an English professor at the Mariano Marcos State University College of Teacher Education (CTE), Laoag City. He is the Program Adviser for English, College Coordinator for Instructional Materials Development Coordinator for Board Licensure Examination for Professional Teachers (BLEPT) Review and the Head Editor of the CTE Research Journal. His papers titled "English Language Needs of Teachers at Bangplama Soongsumarnpadhungwit School, Suphanburi, Thailand," and "Analysis of Errors in the English Writings of Teacher Education Students," were published in the Researchers World: Journal of Arts Science and Commerce in 2014. He also wrote a book titled Literatures of the World: Teaching and Learning in the Constructivist Approach (Quezon City: IPM Publishing, Inc., 2011). His research interests include linguistics, language, literature, language and literature teaching, language and literature assessment, instructional materials development and integration of ICT in education.

Dr. Lasaten is a member of Linguistic Society of the Philippines (LSP), Inc., College English Teachers Association (CETA), Council of the Department Chairpersons for English (CDCE), Philippine Association for Teacher Education (PAFTE), Philippine Association for Language Teaching (PALT), Inc. and International English Learners Training Institute (IELTI). He was awarded the Outstanding Teacher of MMSU in 2014. 